\title{
Cognitive Flexibility and Problem-solving in Patients with Bipolar Disorder
}

\author{
Maria Yoshepa Safira Nugroho ${ }^{1}$ Gladdy L. Woworuntu ${ }^{1}$, B. Handoko Daeng ${ }^{1,2 *}$ \\ ${ }^{1}$ Medical Faculty of Widya Mandala Catholic University, Surabaya, Indonesia \\ ${ }^{2}$ Nursing Faculty of Widya Mandala Catholic University, Surabaya, Indonesia
}

\section{A R T I C L E I N F O}

\section{Article history:}

Received 16 August 2019

Received in revised form 08

September 2019

Accepted 10 October 2019

Available online 31 October 2019

Keywords:

Cognitive flexibility,

Problem-solving,

Bipolar.

\section{*) Corresponding author:}

bhandokodaeng@yahoo.com

\begin{abstract}
A B S T RA C T
Introduction: This study focuses on the cognitive impairment in patients with bipolar disorder and also the distribution of cognitive flexibility and problem-solving by degree of education, chronicity, and episode of patient is in at the time of evaluation.

Methods: This was a cross sectional descriptive study with purposive sampling method. The population was the Harmony in Diversity Group in Surabaya, Indonesia. Twenty-two patients agreed to be subjects and each of them finished the Wisconsin Card Sorting Test (WCST) to measure cognitive flexibility and the Tower of London (TOL) to measure problem-solving.

Results: The WCST score are below normal for $90.9 \%$ of the patients. Higher cognitive flexibility is found in patients with bachelor's degree and euthymic patients, while lower cognitive flexibility is found in patients in depression episode, manic episode, and mixed episode. No patients could finish the TOL within the minimum required steps. Better problem-solving is found in patients in manic episode and euthymic patients while lower problem-solving is found in mixed episode and depressive episode.

Conclusion: The cognitive flexibility and problem-solving in patients with bipolar disorder are lower than the normal cut off. The type of episode and chronicity are contributing factors. Euthymic patients tend to have better cognitive flexibility and manic patients tend to have better problem-solving ability.
\end{abstract}

\section{Introduction}

Bipolar Disorder (BD) was estimated to affect $2.2 \%$ of the population or approximately 5.3 million adults aged 18 or older in the United States in 2014 . About $51 \%$ of people with BD are untreated. ${ }^{1}$ At least $25-50 \%$ of people with BD have attempted suicide at least once, and it reduces 9.2 years of the life expectancy. 2,3

In patients with $\mathrm{BD}$, extreme mood changes in every episode can affect their perception and thinking process, thus affect their flexibility and ability to solve problems. Patients could have trouble adapting as a result of having less cognitive flexibility and having trouble solving their everyday problems. This cognitive disability can affect social function, resulting in psychosocial disability, because cognitive function is also related to functional and emotional domain. ${ }^{4,7}$ According to Lara E, et al. (2015), worse cognitive function is related to more frequent suicidal ideas in patients in depression. ${ }^{8}$

Previous studies have found cognitive impairments in patients with BD. Around 40-60\% patients with BD have clinically significant cognitive impairment. ${ }^{7}$ In a study conducted by Martínez-Arán, et al. (2014), stable bipolar patients showed worse results in memory, attention, and cognitive flexibility tests compared to healthy subjects. ${ }^{9}$
Other studies found that regardless of the episodes the BD patients were in, they showed significant deficit in working memory, episodic memory, spatial attention, attention, problem-solving, executive function, emotional process, and the ability to produce a solution to a social problem. ${ }^{10,12}$

There are still lack of literatures about cognitive flexibility and problem-solving ability in BD patients. Therefore, we aim to see the distribution of cognitive flexibility and problem-solving ability among BD patients in Surabaya.

\footnotetext{
Methods

This study was a cross sectional descriptive study, conducted from June until August 2015. Participants taken purposively from members of the Harmony in Diversity group in Surabaya, Indonesia; a consumers' group for BD. The subjects were patients who had been diagnosed with BD by a psychiatric according to the Indonesian guidelines for psychiatric diagnosis (Pedoman Penggolongan dan Diagnosis Gangguan Jiwa ke-III). Cognitive tests were performed once, without any intervention given to the subjects. Patients with mental retardation, dementia, history of stroke, alcohol use, substance abuse, and history of head trauma were excluded. Cognitive flexibility was measured with the Wisconsin Card Sorting Test (WCST), with the
} 
normal cut off point is $\leq 12,4 \% .^{13,14}$ Problem-solving ability was measured with the Tower of London (TOL) which is supposed to be finished within minimum 63 steps. More steps mean worse problem-solving ability.were conducted for high accuracy.

\section{Results}

Twenty two subjects had been tested, with the characteristics shown on Table 1 . The mean age was $31 \pm 10.23$ years, with the age span of 17 to 48 years old. The mean chronicity of the BD was $9 \pm 7.5$ years. $90 \%$ of the subjects got lower than normal WCST score, which resembled the result of a study conducted by Martínez-Arán, et al. (2014). ${ }^{9}$ No patients could finish the TOL within the minimum required steps.

Table 1. Baseline Characteristics of the Patients

\begin{tabular}{lc}
\hline \multicolumn{1}{c}{ Characteristic } & $\begin{array}{c}\mathbf{n}(\mathbf{\%}) \\
(\mathbf{n = 2 2})\end{array}$ \\
\hline Sex & $9(40.91)$ \\
$\quad$ Male & $13(59.09)$ \\
$\quad$ Female & \\
\hline Age & 0 \\
$<17$ years & $13(59.09)$ \\
17-35 years & $6(27.27)$ \\
36-45 years & $3(13.63)$ \\
46-59 years & 0 \\
$\geq 60$ years & $31 \pm 10.23$ \\
Mean \pm SD &
\end{tabular}

\section{Degree of Education}

Elementary/Junior High/High School

Diploma

Bachelor

$9(40.91)$

\begin{tabular}{cc}
\hline Chronicity & \\
$\leq 2$ years & $6(27.27)$ \\
$>2$ years & $16(72.72)$ \\
Mean \pm SD & $9 \pm 7.50$ \\
\hline
\end{tabular}

\begin{tabular}{lc}
\hline Episode & \\
Manic/Hypomanic & $4(18.18)$ \\
Depression & $3(13.64)$ \\
Mixed & $5(22.73)$ \\
$\quad$ Remission & $10(45.45)$ \\
\hline Cognitive Flexibility & \\
$\leq 12.4 \%$ (normal cut off) & $2(9.09)^{\circ}$ \\
$>12.4 \%$ & $20(90.90)$ \\
Mean SD & $17.58 \pm 5.75$ \\
\hline Problem-solving Ability & \\
$=63$ steps (minimum & $0{ }^{\Delta}$ \\
required steps) & \\
$>63$ steps & $22(100)$ \\
Mean \pm SD & $78 \pm 9.18$ \\
\hline
\end{tabular}

Both are patients in remiision

${ }^{\Delta}$ No patients could finish the TOL within the minimum required steps
The distribution of cognitive flexibility according to degree of education, chronicity, and episode can be seen in Table 2. In terms of education degree, cognitive flexibility was better in subjects with bachelor's degree (mean: $16.12 \pm 2.64 \%$ ), followed by elementary/junior high/high school subjects (mean: 17.88 $\pm 7.53 \%$ ). On the aspect of chronicity, cognitive flexibility was better in patients who have had BD for more than 2 years (mean:15.21 \pm 5.47 ). Meanwhile, better WCST scores were obtained by patients in remission (mean: $14.50 \pm 2.36 \%$, best score is $10 \%$ ) and worse WCST scores were found in patients in mixed episode (mean: $22.67 \pm 9.02 \%$, worst score is $33.34 \%)$.

The distribution of problem-solving ability according to degree of education, chronicity, and episode can be seen in Table 3. The differences of the TOL scores between education groups were not significant. In the chronicity aspect, better problem-solving ability was found in subjects who have had BD for more than 2 years (mean: $74 \pm 7.80$ steps). In terms of episode, problemsolving ability was better in patients in manic episode (mean: $74 \pm 10.40$ steps, best score is 64 steps) and worse was found in patients in mixed episode (mean: $80 \pm 10.66$ steps) and depression episode (mean: $81 \pm 11.50$ steps). Worst TOL score (95 steps) was the result of a patient in mixed episode.

Twenty two subjects had been tested, with the characteristics shown on Table 1 . The mean age was $31 \pm 10.23$ years, with the age span of 17 to 48 years old. The mean chronicity of the BD was $9 \pm 7.5$ years. $90 \%$ of the subjects got lower than normal WCST score, which resembled the result of a study conducted by MartínezArán, et al. (2014). ${ }^{9}$ No patients could finish the TOL within the minimum required steps.

The distribution of cognitive flexibility according to degree of education, chronicity, and episode can be seen in Table 2. In terms of education degree, cognitive flexibility was better in subjects with bachelor's degree (mean: $16.12 \pm 2.64 \%$ ), followed by elementary/junior high/high school subjects (mean: $17.88 \pm 7.53 \%$ ). On the aspect of chronicity, cognitive flexibility was better in patients who have had BD for more than 2 years (mean: 15.21 \pm 5.47$)$. Meanwhile, better WCST scores were obtained by patients in remission (mean: $14.50 \pm 2.36 \%$, best score is 10\%) and worse WCST scores were found in patients in mixed episode (mean: $22.67 \pm 9.02 \%$, worst score is $33.34 \%$ ).

The distribution of problem-solving ability according to degree of education, chronicity, and episode can be seen in Table 3. The differences of the TOL scores between education groups were not significant. In the chronicity aspect, better problem-solving ability was found in subjects who have had BD for more than 2 years (mean: $74 \pm 7.80$ steps). In terms of episode, problemsolving ability was better in patients in manic episode (mean: $74 \pm 10.40$ steps, best score is 64 steps) and worse was found in patients in mixed episode (mean: $80 \pm 10.66$ steps) and depression episode (mean: $81 \pm 11.50$ steps). Worst TOL score (95 steps) was the result of a patient in mixed episode. 
Table 2. Distribution of Cognitive Flexibility in Patients with BD

\begin{tabular}{|c|c|c|c|c|}
\hline \multirow[b]{2}{*}{ Variable } & \multirow[b]{2}{*}{ Groups } & \multicolumn{3}{|c|}{ Wisconsin Card Sorting Test } \\
\hline & & $\begin{array}{c}\leq 12.4 \% \\
\text { n }(\%)\end{array}$ & $\begin{array}{c}>12.4 \% \\
\text { n }(\%)\end{array}$ & Mean \pm SD \\
\hline \multirow{3}{*}{ Degree of Education } & $\begin{array}{l}\text { Elementary/Junior } \\
\text { High/High School }\end{array}$ & $1(9.09)$ & $10(90.91)$ & $17.88 \pm 7.53$ \\
\hline & Diploma & 0 & $2(100)$ & $22.50 \pm 1.17$ \\
\hline & Bachelor & $1(11.11)$ & $8(88.89)$ & $16.12 \pm 2.64$ \\
\hline \multirow{2}{*}{ Chronicity } & $\leq 2$ years & 0 & $6(100)$ & $19.45 \pm 6.56$ \\
\hline & $>2$ years & $2(12.50)$ & $14(87.50)$ & $15.21 \pm 5.47$ \\
\hline \multirow{4}{*}{ Episode } & Manic/Hypomanic & 0 & $4(100)$ & $19.17 \pm 3.97$ \\
\hline & Depression & 0 & $3(100)$ & $17.25 \pm 4.20$ \\
\hline & Mixed & 0 & $5(100)^{\Delta}$ & $22.67 \pm 9.02$ \\
\hline & Remission & $2(25) \cdot$ & $8(75)$ & $14.50 \pm 2.36$ \\
\hline
\end{tabular}

- The best WCST score is $10 \%$, obtained by a patient in remission

${ }^{\Delta}$ The worst WSCT score is $33.34 \%$, obtained by a patients in mixed episode

Table 3. Distribution of Problem-solving Ability in Patients with BD

\begin{tabular}{|c|c|c|c|c|}
\hline \multirow[b]{2}{*}{ Variables } & \multirow[b]{2}{*}{ Groups } & \multicolumn{3}{|c|}{ Tower of London } \\
\hline & & $\begin{array}{c}=63 \text { steps } \bullet \\
\mathrm{n}(\%)\end{array}$ & $\begin{array}{c}>63 \text { steps } \\
\mathrm{n}(\%)\end{array}$ & Mean \pm SD \\
\hline \multirow{3}{*}{ Degree of Education } & $\begin{array}{l}\text { Elementary/Junior } \\
\text { High/High School }\end{array}$ & 0 & $11(100)$ & $77 \pm 10.43$ \\
\hline & Diploma & 0 & $2(100)$ & $81 \pm 11.31$ \\
\hline & Bachelor & 0 & $9(100)$ & $79 \pm 8.10$ \\
\hline \multirow{2}{*}{ Chronicity } & $\leq 2$ years & 0 & $6(100)$ & $81 \pm 12.40$ \\
\hline & $>2$ years & 0 & $16(100)$ & $74 \pm 7.80$ \\
\hline \multirow{4}{*}{ Episode } & Manic/Hypomanic & 0 & $4(100)$ & $74 \pm 10.40$ \\
\hline & Depression & 0 & $3(100)$ & $81 \pm 11.50$ \\
\hline & Mixed & 0 & $5(100)^{\ominus}$ & $80 \pm 10.66$ \\
\hline & Remission & 0 & $10(100)^{\Delta}$ & $78 \pm 8.37$ \\
\hline
\end{tabular}

- No patients could finish the TOL within the minimum required steps

${ }^{\Delta}$ The best TOL score is 64 steps, obtained by a patients in remission

${ }^{\ominus}$ The worst TOL score is 95 steps, obtained by a patient in mixed episode

\section{Discussion}

During the test, few subjects felt that the test was too difficult and almost gave up. Some patients started talking to the examiner about random things and they almost forgot that they were still doing a test, the examiner had to remind them to stay focused on the test. On the contrary, some patients did the test in a hurry, and stopped after realizing that they had made a mistake. They had to retrace their steps, resulting in more steps needed to finish the test. There were also a few patients that did not listen to the examiner's comment during the WCST test. This simple observation shows that patients with BD have difficulties in performing simple tasks. Pessimism, hopelessness, and lack of concentration show depression, meanwhile flight of ideas and excessive energy show manic episode. These extreme moods can affect the patient's emotion and perception, resulting in impaired social cognition. ${ }^{15}$

The WCST and TOL scores in degree of education is not significantly different, this may be because the episode of the patient plays a bigger role in affecting the social cognition. Patients who have had BD for more than 2 years tend to show better scores than the ones who have had for less than 2 years. This result is different from previous study conducted by Torrent C, et al. (2012), which showed that the impairment in attention, psychomotor skills, and verbal memory is stable, but the other executive functions gradually decline in patients with BD. Executive function is found to be related with duration of illness and the presence of sub-depressive symptoms. ${ }^{16}$ In another study by Mur M, et al. (2008), executive function deficits are still stable in 2 years of observation. ${ }^{17}$ In this study, the better result of WCST and TOL in patients who have had BD for more than 2 years may happened because the patients have been treated, adapted, and learned to deal with their unstable mood, compared to patients who have had BD for less than 2 years. Another possibility is that this result does not have any relation to the chronicity of the patient, because 
the course of the disease is different in every patient, with different contributing factors. ${ }^{18}$

In manic episode, the presence of flight of ideas and grandiose ideas will result in stubbornness and difficulty accepting or adapting to different ideas or situations, which will affect the cognitive flexibility. This result was similar to previous studies by Vrabie M, et al. (2015) and Clark L, et al. (2001), which showed that patients in manic episode had worse executive function (including cognitive flexibility). $(19,20)$ On the contrary, manic episode subjects in this study showed better problem-solving ability than other episodes. This was different from prior studies. ${ }^{19,20}$ It might be caused by the increase of energy and optimism in patients in manic episode. According to Bearden CE, et al. (2006), patients in manic episode showed lack of concentration and made decisions impulsively. ${ }^{21}$ If patients' ideas are more logical, not grandiose nor impulsive, this should be able to help them to solve problems better (like in hypomanic episode). As stated by Abé C, et al. (2015), there is a decreased brain mass in patients in manic episode which is not found in patients without manic episode. Unfortunately, this study did not observe hypomanic patients. ${ }^{22}$

In depression episode, the pessimistic thoughts and hopelessness could make the patient decline any new ideas, resulting in decreased cognitive flexibility. Meanwhile, loss of interest, low self-esteem and worthlessness could impede patient's problem-solving ability. Kapczinski NS, et al. (2016) had demonstrated that the impairment of executive function is worse in patients with severe depression compared to moderate depression. ${ }^{23}$ This study did not observe the severity of the depression episode in patients with BD. Depp CA, et al. (2016), stated that there are three pathways of cognitive impairment in bipolar depression; (1) Sustained and recurrent mood symptoms may directly impact neurobiological pathways that diminish cognitive ability; (2) Mood symptoms may indirectly contribute to and exacerbate negative health behaviors that impact cognitive ability; and (3) Disability may reciprocally impact the determinants of cognitive deficits and depressive symptoms.

In mixed episode, patients experience symptoms of elevated and decreased mood at the same time, or the mood exchanges rapidly. The WCST score in patients in mixed episode was shown to be the worst, and the TOL score showed a decline in problem-solving ability. This resembles the study by Vrabie M, et al. (2015) where patients in mixed episode got lower scores in executive function tests (including cognitive flexibility) and problem-solving ability. ${ }^{14}$ According to Berk M, et al. (2005) and Sax KW, et al. (1995), the presence of both manic and depressive symptoms worsen the cognitive deficit in patients in mixed episodes. ${ }^{24,25}$

In remission, the patient's mood is stable, no elevation or depletion. Patient will be more open-minded and adaptable, which results in better cognitive flexibility. Compared to other episodes, the WCST score of patients in remission are the best. Still, $75 \%$ of the patients in remission have impaired WCST score compared to the normal cut off score, and no patients in remission could finish the TOL within the minimum required steps. This was in line with the study by Vrabie M, et al. (2015), which showed that
BD patients in remission shown better scores than other episodes, but still significantly worse than the control group. ${ }^{14}$ There is evidence of cognitive deficit in patients in remission and this supports the idea that euthymic phase is not necessarily an improvement period. . $26,27,28$

The cognitive deficit in patients with $\mathrm{BD}$ can be the result of several factors like younger age of onset, higher number of previous episodes, higher numbers of previous hospitalizations, and greater presence of psychotic features. ${ }^{18}$ Some studies found a change in the prefrontal and frontal cortex and decreased brain mass in patients with BD. ${ }^{12,19,20,22}$ Prefrontal cortex is found to be more active in healthy subjects compared to patients with BD. The frontal cortex is important in changing the behavior of a patient from a routine response into a new and flexible response, adapting to new situations. This frontal cortex will become smaller if BD is uncontrolled. ${ }^{4}$

Even though patients have had regular therapy and stable mood, cognitive function will still be impaired. To improve cognitive function, patients with $\mathrm{BD}$ should be given cognitive therapies. Cognitive therapy is important in managing $\mathrm{BD}$, because cognitive function is a critical factor in psychosocial disability, which will impact the patient's quality of life. ${ }^{4}$ A study by Veeh J, et al. (2017), showed that cognitive remediation could help improve the executive function of BD patients. Cognitive remediation also has positive effects on residual symptoms. ${ }^{29}$ An intensive therapy for $\mathrm{BD}$ patients is important to improve cognitive deficits. ${ }^{23}$ There is also a functional remediation therapy for patients in remission which can improve the functional outcome. ${ }^{5}$

Limitation of this study is that the small number of participants made it difficult to control the variable (age, degree of education, number of episodes, medication and therapy). Another study with a bigger number and homogenous sample should be conducted to test the correlation of the variables.

\section{Conclusion}

In patients with $\mathrm{BD}$, cognitive flexibility and problemsolving ability are lower than the normal cut off. The episode and chronicity of the patient are among the contributing factors. Patients in remission tend to have better cognitive flexibility, and patients in manic episode tend to have better problem-solving ability. Patients in depression episode tend to have worse problem-solving ability and patients in mixed episode tend to have worse cognitive flexibility and problem-solving ability. Patients who have had BD for more than 2 years had better cognitive flexibility and problem-solving ability.

\section{Conflict of Interest}

The author would like to declare that there is no conflict of interest in conducting this study.

\section{References}

1. Treatment Advocacy Center Bipolar Disorder - Fact Sheet [Internet]. 2018. Available from: https:/www.treatmentadvocacycenter.org/ evidence-and-research/learn-more-about/463-bipolar-disorder-factsheet

2. Jamison K. Suicide and bipolar disorder. J Clin Psychiatry [Internet]. 2000;61(9):47-51. 
3. Depression and Bipolar Support Alliance (Institution/Organization). Bipolar Disorder [Internet]. 2019. Available from: https:/www. dbsalliance.org/education/bipolar-disorder/

4. Solé B, Jiménez E, Torrent C, Reinares M, Bonnin CDM, Torres I, et al. Cognitive Impairment in Bipolar Disorder: Treatment and Prevention Strategies. Int J Neuropsychopharmacol. 2017 Aug;20(8):670-80.

5. Torrent C, Bonnin C del M, Martinez-Aran A, Valle J, Amann BL, Gonzalez-Pinto A, et al. Efficacy of functional remediation in bipolar disorder: a multicenter randomized controlled study. Am J Psychiatry. 2013 Aug;170(8):852-9.

6. Lima IMM, Peckham AD, Johnson SL. Cognitive deficits in bipolar disorders: Implications for emotion. Clin Psychol Rev. 2018 Feb;59:126-36.

7. Depp CA, Dev S, Eyler LT. Bipolar Depression and Cognitive Impairment: Shared Mechanisms and New Treatment Avenues. Psychiatr Clin North Am [Internet]. 2015/12/11. 2016 Mar;39(1):95109.

8. Lara E, Olaya B, Garin N, Ayuso-Mateos JL, Miret M, Moneta V, et al. Is cognitive impairment associated with suicidality? A populationbased study. Eur Neuropsychopharmacol. 2015 Feb;25(2):203-13.

9. Martínez-Arán A, Vieta E, Colom F, Torrent C, Sánchez-Moreno J, Reinares M, et al. Cognitive impairment in euthymic bipolar patients: implications for clinical and functional outcome. Bipolar Disord [Internet]. 2004;6(3):224-32.

10. Sweeney J, Kmiec J, Kupfer D. Neuropsychologic impairments in bipolar and unipolar mood disorders on the CANTAB neurocognitive battery. Biol Psychiatry [Internet]. 2000;48(7):674-84.

11. Scott J, Stanton B, Garland A, Ferrier I. Cognitive vulnerability in patients with bipolar disorder. Psychol Med [Internet]. 2000;30(2):467-72.

12. Clark L, Sahakian BJ. Cognitive neuroscience and brain imaging in bipolar disorder. Dialogues Clin Neurosci [Internet]. 2008 Jun;10(2):153-63.

13. Nuffield Foundation. Investigating the Wisconsin Card Sorting Test [Internet]. 2019. Available from: https://www.nuffieldfoundation.org/ applied-science/investigating-wisconsin-card-sorting-test

14. Heaton RK, Chelune GJ, Talley JL, Kay GG, Curtiss G. The Wisconsin Card Sorting Test Manual. Psychological Assessment Resources, Inc.; 1993.

15. Temmerman A, Sabbe B, Morrens M. Social cognition in bipolar disorder. Tijdschr Psychiatr [Internet]. 2015;57(6):405-14.

16. Torrent C, Martinez-Aran A, Bonnin C del M, Reinares M, Daban C, Solé B, et al. Long-Term Outcome of Cognitive Impairment in Bipolar Disorder. J Clin Psychiatry. 2012;73(7):e899-905.
17. Mur M, Portella MJ, Martinez-Aran A, Pifarré J, Vieta E. Long-Term Stability of Cognitive Impairment in Bipolar Disorder: A 2-Year Follow-Up Study of Lithium-Treated Euthymic Bipolar Patients. J Clin Psychiatry. 2008;69(5):712-9.

18. Abdel Aal M, Molokhia T, El Kholy O, Sheshtawy H. Cognitive dysfunction in depressive and mixed episodes of bipolar disorder and major depressive disorder: is there a difference? egyptian experience. Egypt J Psychiatry [Internet]. 2018 Jan 1;39(1):28-34.

19. Vrabie M, Marinescu V, Talaşman A, Tăutu O, Drima E, Micluţia I. Cognitive impairment in manic bipolar patients: important, understated, significant aspects. Ann Gen Psychiatry [Internet]. 2015 Nov $25 ; 14: 41$.

20. Clark L, Iversen SD, Goodwin GM. A Neuropsychological Investigation of Prefrontal Cortex Involvement in Acute Mania. Am J Psychiatry [Internet]. 2001 Oct 1;158(10):1605-11.

21. Bearden CE, Glahn DC, Monkul ES, Barrett J, Najt P, Kaur S, et al. Sources of declarative memory impairment in bipolar disorder: mnemonic processes and clinical features. J Psychiatr Res. 2006 Feb;40(1):47-58.

22. Abé C, Ekman C-J, Sellgren C, Petrovic P, Ingvar M, Landen M. Manic episodes are related to changes in frontal cortex: a longitudinal neuroimaging study of bipolar disorder 1. Brain. 2015 Nov;138(Pt 11):3440-8.

23. Kapczinski NS, Narvaez JC, Magalhaes P V, Bucker J, Peuker AC, Loredo AC, et al. Cognition and functioning in bipolar depression. Rev Bras Psiquiatr. 2016;38(3):201-6.

24. Berk M, Dodd S, Malhi GS. 'Bipolar Missed States': The Diagnosis and Clinical Salience of Bipolar Mixed States. Aust New Zeal J Psychiatry [Internet]. 2005 Apr 1;39(4):215-21.

25. Sax KW, Strakowski SM, McElroy SL, Keck Jr. PE, West SA. Attention and formal thought disorder in mixed and pure mania. Biol Psychiatry [Internet]. 1995 Mar 15;37(6):420-3.

26. Clark L, Iversen SD, Goodwin GM. Sustained attention deficit in bipolar disorder. $\mathrm{Br} \mathrm{J}$ Psychiatry [Internet]. 2018/01/02. 2002;180(4):313-9.

27. Daglas R, Yücel M, Cotton S, Allott K, Hetrick S, Berk M. Cognitive impairment in first-episode mania: a systematic review of the evidence in the acute and remission phases of the illness. Int J bipolar Disord [Internet]. 2015 Apr 25;3:9.

28. Latalova K, Prasko J, Diveky T, Velartova H. Cognitive impairment in bipolar disorder. Biomed Pap [Internet]. 2011;155(1):19-26.

29. Veeh J, Kopf J, Kittel-Schneider S, Deckert J, Reif A. Cognitive remediation for bipolar patients with objective cognitive impairment: a naturalistic study. Int J bipolar Disord [Internet]. 2017 Apr 13;5(1):8. 